\title{
Investigating the Applicability of qALPV Modeling to ICU Models for Glycaemic Control
}

\author{
Levente Kovács*, András György*, Péter Szalay*, Balázs Benyó*, \\ Zoltán Benyó*, Christopher E. Hann**, J. Geoffrey Chase**

\begin{abstract}
*Budapest University of Technology and Economics, Dept. of Control Engineering and Information Technology Magyar tudósok krt. 2, Budapest, H-1117 Hungary(Tel: +36-1-463-4027; e-mail: lkovacs@iit.bme.hu, gyorgya@iit.bme.hu, phi.theta.psi@gmail.com,bbenyo@iit.bme.hu,benyo@iit.bme.hu

** Dept. of Mechanical Engineering, Centre for Bio-Engineering, University of Canterbury,
\end{abstract} \\ Christchurch,New Zealand (e-mail: chris.hann@canterbury.ac.nz,geoff.chase@canterbury.ac.nz)
}

\begin{abstract}
Maintenance of glucose levels in intensive care unit (ICU) patients via control of insulin inputs is currently an active research field. Different published models that address this problem are analysed from control theory point of view. This paper analyzes the three most used ICU metabolic system models in the literature, two of which have been validated in clinical trials or alternate clinical use. Global control theoretical characteristics are determined using nonlinear analysis. Quasi affine linear parameter varying (qALPV) modeling methodology is then investigated for further robust nonlinear model based control.
\end{abstract}

Keywords: diabetes, tight glycaemic control, nonlinear analysis, qALPV.

\section{INTRODUCTION}

Critically ill patients admitted to the Intensive Care Unit (ICU) often display hyperglycaemia and insulin resistance associated with adverse outcomes, which are associated with increased morbidity and mortality (Capes et al 2000). Consequently, tight glycaemic control (TGC) can reduce these adverse outcomes (van den Berghe 2001; Chase et al 2008), as well as reducing economic costs (van den Berghe 2006). Hence, TGC using model-based methods has become an active research field (Chase et al 2006).

Several studies have reduced mortality using TGC (van den Berghe 2001; Chase et al 2008), but several others have reported difficulty repeating these results (Griesdale 2009). This difficulty, due in large part to the significant metabolic variability of ICU patients (Lin et al 2008), thus presents an ideal application for model-based automation of insulin infusions for TGC.

Therefore, accurate metabolic system models are a critical element. The best known model is the minimal model of (Bergman et al 1981), which is used primarily for clinical research studies. However, the model's simplicity is a disadvantage, with significant important components of glucose-insulin interaction neglected in its formulation, as they are not required or are managed in clinical experiments. Consequently, different models were derived from the minimal model, trying to generalize / extend the validity for the ICU case. Wong et al (2006) and Lotz et al (2006) presented a third order model that better captured insulin losses and saturation dynamics. Van Herpe et al (2007) created a fourth order model that accounted for further typical features of the ICU patient in their ICU Minimal Model, although basic structure was retained. Of these three models only those of Wong et al and Lotz et al have been clinically applied and validated in TGC for ICU patients, as well as in other clinical experiments similar to those for which the Minimal Model is used.

This paper investigates these models' global control characteristics using nonlinear analysis. The transformation of the mentioned models in quasi affine linear parameter varying (qALPV) form is also examined to assess the ability to design a robust, nonlinear model-based controller. Hence, it provides a unique control theoretic analysis of these models.

\section{ICU MODELS}

\subsection{Minimal Model of Bergman et al}

Derived from the two-compartment minimal model created by Bergman et al (1979) a three-compartment approach was developed for use in clinical research experiments to determine insulin sensitivity in man (Bergman et al 1981). This extended model contains an additional state variable representing the insulin utilization of the "distant" compartment. The system is defined:

$$
\begin{aligned}
& \dot{G}(t)=p_{1} G(t)-X(t)\left(G(t)+G_{b}\right)+h(t) \\
& \dot{X}(t)=-p_{2} X(t)+p_{3} Y(t) \\
& \dot{Y}(t)=p_{4}\left(Y(t)-Y_{b}\right)+\frac{i(t)}{V_{L}}
\end{aligned}
$$

where the parameters are defined Table 1, including typical values found in experiments or used as constants. 
Table 1. Variables used in the extended Bergman-model.

\begin{tabular}{|c|c|c|c|}
\hline Notation & Unit & Description & Value \\
\hline \hline$G$ & $\mathrm{mg} / \mathrm{dL}$ & $\begin{array}{c}\text { Plasma glucose } \\
\text { concentration }\end{array}$ & - \\
\hline$Y$ & $\mathrm{mU} / \mathrm{dL}$ & $\begin{array}{c}\text { Plasma insulin } \\
\text { concentration }\end{array}$ & - \\
\hline$X$ & $\mathrm{mU} / \mathrm{dL}$ & $\begin{array}{c}\text { "Distant" compartment } \\
\text { insulin concentration }\end{array}$ & - \\
\hline \hline \multicolumn{5}{|c|}{ Model inputs } \\
\hline$h$ & $\mathrm{mg} / \mathrm{dL}$ & $\begin{array}{c}\text { Intravenous glucose } \\
\text { injected }\end{array}$ & - \\
\hline$i$ & $\mathrm{mU} / \mathrm{min}$ & $\begin{array}{c}\text { Intravenous insulin } \\
\text { injected }\end{array}$ & - \\
\hline \hline \multicolumn{5}{|c|}{ Parameters } \\
\hline$G_{b}$ & $\mathrm{mg} / \mathrm{dL}$ & $\begin{array}{c}\text { Basal level glucose } \\
\text { concentration }\end{array}$ & 110 \\
\hline$Y_{b}$ & $\mathrm{mU} / \mathrm{dL}$ & $\begin{array}{c}\text { Basal level insulin } \\
\text { concentration }\end{array}$ & 1.5 \\
\hline$V_{L}$ & $\mathrm{dL}$ & $\begin{array}{c}\text { Volume of insulin } \\
\text { space }\end{array}$ & 120 \\
\hline$p_{1}$ & $1 / \mathrm{min}$ & Rate parameter & 0.028 \\
\hline$p_{2}$ & $1 / \mathrm{min}$ & Rate parameter & 0.025 \\
\hline$p_{3}$ & $1 / \mathrm{min}$ & Rate parameter & 0.00013 \\
\hline$p_{4}$ & $1 / \mathrm{min}$ & Rate parameter & $5 / 54$ \\
\hline
\end{tabular}

\subsection{Canterbury Model}

Chase and colleagues at the University of Canterbury developed a series of models based on a fundamental system with three compartments (Wong et al 2006; Lin et al 2008; Le Compte et al 2009), where the additional state variable represents insulin bounded to interstitial sites. Moreover, the model captures insulin losses to the liver and kidneys (Lotz et al, 2006) and saturation dynamics through the use of Michaelis-Menten functions. Its unique insulin sensitivity metric (Hann et al, 2005) is highly correlated to the value derived from the gold-standard euglycemic clamp (Lotz et al, 2006). The model is defined:

$$
\begin{aligned}
& \dot{G}(t)=-p_{G} G(t)-S_{I}(t)\left(G(t)+G_{E}\right) \frac{Q(t)}{1+\alpha_{G} Q(t)}+P(t) \\
& \dot{Q}(t)=k I(t)-k Q(t) \\
& \dot{I}(t)=-\frac{n I(t)}{1+\alpha_{I} I(t)}+\frac{u_{e x}(t)}{V}
\end{aligned}
$$

where the parameters are defined in Table 2, including typical values assigned to population constants. The insulin sensitivity metric is identified in real-time from data (Hann et al, 2005). In particular, patient specific profiles for timevarying $S_{I}$ and $p_{G}$ can be created by fitting retrospective glucose, insulin and feed data, where $p_{G}$ accounts for both endogenous clearance and the net impact of endogenous glucose production on removal.

Note that Equation (2/c) does not include endogenous insulin or glucose production, although later model versions do (e.g. Lotz et al 2008; Le Compte et al 2009). Each model version manages these differently but with consistent prediction

\begin{tabular}{|c|c|c|c|}
\hline Notation & Unit & Description & Value \\
\hline \multicolumn{4}{|c|}{ State variables } \\
\hline$G$ & $\mathrm{mmol} / \mathrm{L}$ & $\begin{array}{c}\text { Plasma glucose above } \\
\text { equilibrium level }\end{array}$ & - \\
\hline$Q$ & $\mathrm{mU} / \mathrm{L}$ & $\begin{array}{l}\text { Concentration of } \\
\text { insulin bounded to } \\
\text { interstitial sites }\end{array}$ & - \\
\hline$I$ & $\mathrm{mU} / \mathrm{L}$ & $\begin{array}{c}\text { Plasma insulin } \\
\text { resulting from external } \\
\text { input } \\
\end{array}$ & - \\
\hline \multicolumn{4}{|c|}{ Model inputs } \\
\hline$P$ & $\underset{\mathrm{n}}{\mathrm{mmol} / \mathrm{L} / \mathrm{mi}}$ & $\begin{array}{c}\text { total plasma glucose } \\
\text { input }\end{array}$ & - \\
\hline$u_{e x}$ & $\mathrm{mU} / \mathrm{min}$ & External insulin & - \\
\hline \multicolumn{4}{|c|}{ Parameters } \\
\hline$G_{E}$ & $\mathrm{mmol} / \mathrm{L}$ & $\begin{array}{c}\text { Plasma equilibrium } \\
\text { level }\end{array}$ & 10.5 \\
\hline$p_{G}$ & $1 / \mathrm{min}$ & $\begin{array}{l}\text { Endogenous glucose } \\
\text { clearance }\end{array}$ & 0.01 \\
\hline$S_{I}$ & $\mathrm{~L} / \mathrm{mU} / \mathrm{min}$ & Insulin sensitivity & 0.001 \\
\hline$V$ & $\mathrm{~L}$ & $\begin{array}{l}\text { Insulin distribution } \\
\text { volume }\end{array}$ & 12 \\
\hline$k$ & $1 / \mathrm{min}$ & $\begin{array}{l}\text { Effective life of insulin } \\
\text { in the compartment }\end{array}$ & 0.0198 \\
\hline$n$ & $1 / \mathrm{min}$ & $\begin{array}{l}\text { First order decay rate } \\
\text { from plasma }\end{array}$ & 0.16 \\
\hline$\alpha_{I}$ & $\mathrm{~L} / \mathrm{mU}$ & $\begin{array}{l}\text { Plasma insulin } \\
\text { disappearance }\end{array}$ & 0.0017 \\
\hline$\alpha_{G}$ & $\mathrm{~L} / \mathrm{mU}$ & Insulin effect & 0.0154 \\
\hline
\end{tabular}
errors of less than $7-10 \%$.
Table 2. Variables used in the Chase-model.

\subsection{Van Herpe - model}

The model of van Herpe et al (2007) uses four state variables to take into consideration some typical features of ICU patients. In particular, the Minimal Model gives the best performance during intravenous glucose tolerance test (IVGTT) with a single shot of glucose. However, in the ICU case the goal is to handle a series of shots. Hence, the endogenous insulin section of the Minimal Model has been transformed into a set of two equations, which also contains a part representing endogenous insulin secretion. Moreover, due to the fact that most of the critically ill patients are nondiabetic and as a result, the endogenous insulin section is still active, the Minimal Model has to be extended with exogenous part as well. Consequently, the model is defined as follows, van Herpe et al (2007):

$$
\begin{aligned}
& \dot{G}(t)=-\left(P_{1}+X(t)\right) G(t)+P_{1} G_{b}+\frac{F_{G}(t)}{V_{G}} \\
& \dot{X}(t)=-P_{2} X(t)+P_{3}\left(I_{1}(t)-I_{b}\right) \\
& \dot{I}_{1}(t)=\alpha \max \left(0, I_{2}\right)-n\left(I_{1}(t)-I_{b}\right)+\frac{F_{I}(t)}{V_{I}} \\
& \dot{I}_{2}(t)=\beta \gamma(G(t)-h)-n I_{2}(t)
\end{aligned}
$$

where parameter values, units and descriptions are given in Table 3. 
Table 3. Variables used in the Van Herpe-model.

\begin{tabular}{|c|c|c|c|}
\hline Notation & Unit & Description & $\begin{array}{l}\text { Used } \\
\text { value }\end{array}$ \\
\hline \multicolumn{4}{|c|}{ State variables } \\
\hline$G$ & $\mathrm{mg} / \mathrm{dL}$ & $\begin{array}{l}\text { Glucose concentration } \\
\text { in plasma }\end{array}$ & - \\
\hline$X$ & $1 / \mathrm{min}$ & $\begin{array}{l}\text { Effect of insulin on net } \\
\text { glucose disappearance }\end{array}$ & - \\
\hline$I_{1}$ & $\mu \mathrm{U} / \mathrm{mL}$ & $\begin{array}{c}\text { Insulin concentration in } \\
\text { plasma }\end{array}$ & - \\
\hline$I_{2}$ & $\mu \mathrm{U} / \mathrm{mL}$ & $\begin{array}{l}\text { Insulin concentration } \\
\text { delivered from } \\
\text { endogenous insulin } \\
\text { secretion }\end{array}$ & - \\
\hline \multicolumn{4}{|c|}{ Model inputs } \\
\hline$F_{G}$ & $\mathrm{mg} / \mathrm{min}$ & Glucose calories flow & - \\
\hline$F_{I}$ & $\mu \mathrm{U} / \mathrm{min}$ & Exogenous insulin & - \\
\hline \multicolumn{4}{|c|}{ Parameters } \\
\hline$B M$ & $\mathrm{~kg}$ & Body mass & 75 \\
\hline$V_{G}$ & $\mathrm{dL}$ & $\begin{array}{l}\text { Glucose distribution } \\
\text { volume }\end{array}$ & $1.6 \mathrm{BM}$ \\
\hline$V_{I}$ & $\mathrm{~mL}$ & $\begin{array}{l}\text { Insulin distribution } \\
\text { volume }\end{array}$ & 120BM \\
\hline$G_{b}$ & $\mathrm{mg} / \mathrm{dL}$ & $\begin{array}{l}\text { Basal value of plasma } \\
\text { glucose }\end{array}$ & 100 \\
\hline$I_{b}$ & $\mu \mathrm{U} / \mathrm{mL}$ & $\begin{array}{l}\text { Basal value of plasma } \\
\text { insulin }\end{array}$ & \\
\hline$P_{1}$ & $1 / \mathrm{min}$ & Glucose effectiveness & 0.0131 \\
\hline$P_{2}$ & $1 / \mathrm{min}$ & $\begin{array}{c}\text { Rate of net remote } \\
\text { insulin disappearance }\end{array}$ & 0.0135 \\
\hline$P_{3}$ & $\mathrm{~mL} /\left(\min ^{2} \mu \mathrm{U}\right)$ & $\begin{array}{c}\text { Rate of insulin- } \\
\text { dependent increase }\end{array}$ & $2.910^{-6}$ \\
\hline$h$ & $\mathrm{mg} / \mathrm{dL}$ & $\begin{array}{c}\text { Glucose threshold } \\
\text { level }\end{array}$ & 136 \\
\hline$n$ & $1 / \mathrm{min}$ & $\begin{array}{c}\text { Time constant of } \\
\text { insulin disappearance }\end{array}$ & 0.13 \\
\hline$\alpha$ & $1 / \mathrm{min}$ & Scaling factor & 3.11 \\
\hline$\beta$ & $\min$ & Model coefficient & 1 \\
\hline$\gamma$ & $\frac{\frac{\mu U}{m L} \frac{d l}{m g}}{\min ^{2}}$ & $\begin{array}{l}\text { Rate of endogenous } \\
\text { insulin release }\end{array}$ & $\begin{array}{l}5.36 \\
10^{-3}\end{array}$ \\
\hline
\end{tabular}

\section{NONLINEAR ANALYSIS}

In this section, global characteristics of the models presented are examined, including reachability and observability according terminology used in (Isidori 1995) for nonlinear analysis. The nonlinear systems are considered to be in the form:

$$
\begin{aligned}
& \dot{x}=f(x)+\sum_{i=1}^{m} g_{i}(x) u_{i} \\
& y_{i}=h_{i}(x) \quad i=1,2, \ldots, m
\end{aligned}
$$

It can be seen that the system is considered to be input affine, where $x$ denote that state vectors, $u_{i}$ the inputs and $y_{i}$ the outputs of the model.

\subsection{Reachability}

Let $\Delta^{C}$ be a nonsingular involutive distribution of dimension $d$ and assume that $\Delta^{C}$ is invariant under the vector fields $f, g_{1}, g_{2}, \ldots, g_{m}$. Moreover, suppose that the distribution $\operatorname{span}\left\{g_{1}, \ldots, g_{m}\right\}$ is contained in $\Delta^{C}$. Then, for each point $x^{0}$ it is possible to find a neighbourhood $U^{0}$ of $x^{0}$ and a local coordinate transformation $z=\Psi(x)$ defined on $U^{0}$ such that, in the new coordinates, the control system (4) is represented by equations of the form:

$$
\begin{aligned}
& \dot{\varsigma}_{1}=f_{1}\left(\varsigma_{1}, \varsigma_{2}\right)+\sum_{i=1}^{m} g_{1 i}\left(\varsigma_{1}, \varsigma_{2}\right) u_{i} \\
& \dot{\varsigma}_{2}=f_{2}\left(\varsigma_{2}\right) \\
& y_{i}=h_{i}\left(\varsigma_{1}, \varsigma_{2}\right) \quad i=1,2, \ldots, m
\end{aligned},
$$

where $\varsigma_{1}=\left(z_{1}, z_{2}, \ldots, z_{d}\right)$ and $\varsigma_{2}=\left(z_{d+1}, z_{d+2}, \ldots, z_{n}\right)$. In this manner, state vector $\varsigma_{1}$ is locally reachable, whereas $\varsigma_{2}$ cannot be controlled (Isidori 1995).

In order to construct the $\Delta^{C}$ distribution, initialization is:

$\Delta_{0}^{C}=\operatorname{span}\left\{g_{1}, \ldots, g_{m}\right\}$.

Then, until rank $\Delta_{k}^{C}$ increases:

$$
\Delta_{k+1}^{C}=\Delta_{k}^{C}+\sum_{i=1}^{q}\left[\tau_{i}, \Delta_{k}^{C}\right],
$$

where $\tau_{i} \in \Delta_{k}^{C}, i=1,2, \ldots, q\left(\operatorname{dim} \Delta_{k}^{C}=q\right)$.

The number of local reachable state variables is the rank of $\Delta^{C}$, (Isidori 1995). In other words, determining the degree of reachability means that new vectors have to be determined using Lie-derivatives, and the dimension that the extended vector field spans is the number of local reachable states.

\subsection{Observability}

Let $d \not P(x) \subset\left(R^{n}\right)^{*}$ denote the subspace containing $d \alpha(x)$ row vectors, where $\alpha \in O$ (observation space).

Then, for each point $x^{0}$ it is possible to find a neighbourhood $U^{0}$ of $x^{0}$, where $d \Delta^{O}(x)=d<n$ for $\forall x \in U^{0}$ and a local coordinate transformation $z=\Psi(x)$ defined on $U^{0}$ such that, in the new coordinates, the control system (4) is represented by equations of the form:

$$
\begin{aligned}
& \dot{\varsigma}_{1}=f_{1}\left(\varsigma_{1}\right)+\sum_{i=1}^{m} g_{1 i}\left(\varsigma_{1}\right) u_{i} \\
& \dot{\varsigma}_{2}=f_{2}\left(\varsigma_{1}, \varsigma_{2}\right)+\sum_{i=1}^{m} g_{2 i}\left(\varsigma_{1}, \varsigma_{2}\right) u_{i}, \\
& y_{i}=h_{i}\left(\varsigma_{1}\right) \quad i=1,2, \ldots, m
\end{aligned}
$$


Table 4. Control properties of the considered three ICU models.

\begin{tabular}{|c|c|c|c|}
\hline $\begin{array}{c}\text { Name of the } \\
\text { model }\end{array}$ & Dimension & Reachability & Observability \\
\hline $\begin{array}{c}\text { Bergman } \\
\text { minimal model }\end{array}$ & 3 & 3 & 2 \\
\hline $\begin{array}{c}\text { Canterbury- } \\
\text { model }\end{array}$ & 3 & 3 & 2 \\
\hline $\begin{array}{c}\text { Van Herpe- } \\
\text { model }\end{array}$ & 4 & 4 & 2 \\
\hline
\end{tabular}

where $\varsigma_{1}=\left(z_{1}, z_{2}, \ldots, z_{d}\right)$ and $\varsigma_{2}=\left(z_{d+1}, z_{d+2}, \ldots, z_{n}\right)$, and the system is considered to be input affine. Consequently, state vector $\varsigma_{1}$ is locally observable, whereas $\varsigma_{2}$ cannot be observed (Isidori 1995).

In order to construct the $d \Delta^{O}$ codistribution, $O$ observation space has to be extended with Lie-derivatives of $h_{i}$, until rank $d \Delta^{O}$ increases. The number of local observable states is the rank of $d \Delta^{P}$, (Isidori 1995). In other words, similar to the previous case, determining the degree of observability means that new covectors have to be determined using Liederivatives, and the dimension that the extended covector field spans is the number of local observable state variables.

\subsection{Results of Nonlinear Analysis}

Applying the nonlinear analysis in accordance with (Isidori 1995), for the ICU models presented in Section 2, the above mentioned nonlinear control characteristics were investigated. Results are summarized in Table 4.

It can be seen that all the models are completely reachable, although the Van Herpe - model has to be extended with the vector:

$$
\mathrm{f}^{\mathrm{new}}=\left[\begin{array}{llll}
\frac{\mathrm{x}_{2}}{120} & 0 & 0 & -0.4217
\end{array}\right]^{\mathrm{T}} .
$$

Moreover, all the models are partially observable, namely only two states can be reconstructed based on measurements. This is in accordance with physiological reasons too, as plasma glucose can be easily measured, while plasma insulin can be estimated (if it is necessary) by knowing the insulin input.

\section{LPV MODELLING AND QALPV DESCRIPTION}

Linear Parameter Varying (LPV) system is a class of nonlinear systems, where the parameter could be an arbitrary time varying, piecewise-continuous and vector valued function denoted by $\rho(t)$, defined on a compact set $\mathscr{P}$.

Consequently, LPV systems provide a model paradigm that goes beyond the classical representation of nonlinear and linear systems. Systems with different parameter variations as non-stationary, nonlinear behavior, dependence on external variables or fast movements between different operating regimes can be handled by LPV framework. Basically, LPV systems can be seen as an extension of linear time-invariant (LTI) systems, where the relations are considered to be linear, but model parameters are assumed to be functions of a timevarying signal.

In order to evaluate the system, the parameter trajectory is required to be known either by measurement or by computation.

\subsection{LPV system definition}

Definition. For a compact $\mathscr{P} \subset \mathbf{R}{ }^{s}$, the parameter variation set $F_{P}$ denotes the set of all piecewise continuous functions mapping $\mathbf{R}^{+}$(time) into $\mathcal{P}$ with a finite number of discontinuities in any interval. The compact set $P \subset \mathbf{R}^{s}$ along with the continuous functions $A: \mathbf{R}^{s} \rightarrow \mathbf{R}^{n \times n}, B: \mathbf{R}{ }^{s}$ $\rightarrow \mathbf{R}^{n \times n_{u}}, C: \mathbf{R}^{s} \rightarrow \mathbf{R}^{n_{y} \times n}, D: \mathbf{R}^{s} \rightarrow \mathbf{R}^{n_{y} \times n_{u}}$ represent an $n^{\text {th }}$ order LPV system whose dynamics evolve as:

$\dot{x}(t)=A(\rho) x(t)+B(\rho) u(t)$

$y(t)=C(\rho) x(t)+D(\rho) u(t)$,

with $\rho(t) \in F_{P}$ named as scheduling variables, (Wu et al. 2000).

As a result, it can be seen that in the LPV model by choosing parameter variables the system's nonlinearity can be hidden, while the measured parameters assure describing the whole working domain of the designed controller. This methodology is used on different control solutions, like (Balas 2002), which gave also a solution of the problem.

\section{2 qALPV modelling}

There are different descriptions of the LPV systems (Kulcsar 2005). In the quasi affine description possibility, a part of the state vector $x(t)$ is equal with the $\rho(t)$ scheduling parameters.

The affine dependency of (11) with $\operatorname{dim}(\rho(t))=N$ means:

$$
\begin{aligned}
& A(\rho)=A_{0}+\rho_{1} A_{1}+\ldots+\rho_{N} A_{N} \\
& B(\rho)=B_{0}+\rho_{1} B_{1}+\ldots+\rho_{N} B_{N} \\
& C(\rho)=C_{0}+\rho_{1} C_{1}+\ldots+\rho_{N} C_{N} \\
& D(\rho)=D_{0}+\rho_{1} D_{1}+\ldots+\rho_{N} D_{N}
\end{aligned}
$$

Hence, the affine LPV system can be written as:

$$
\Sigma(t)=\left\{\Sigma_{0}+\sum_{i=1}^{N} \rho_{i} \Sigma_{i}: \rho_{i} \in\left[\rho_{i} \bar{\rho}_{i}\right], \dot{\rho}_{i} \in\left[\dot{\rho}_{i} \dot{\bar{\rho}}_{i}\right]\right\},
$$

with $\Sigma_{i}=\left[\begin{array}{cc}A_{i} & B_{i} \\ C_{i} & D_{i}\end{array}\right]$, and $i=1,2, \ldots, n$.

In (13) the parameters are varying between known minimal $\left(\underline{\rho}_{i}\right)$ and maximal $\left(\bar{\rho}_{i}\right)$ bounds (respectively the limits of theirs rates are known). 


\section{5. qALPV APPLICABILITY OF ICU MODELS}

In the followings, the definition of the scheduling parameters of the considered models is investigated as key point in LPV (qALPV) modeling methodology.

\section{1 qALPV modelling of the Minimal model of Bergman et al}

The remote compartment insulin utilization $X(t)$, which cannot be measured, can be considered a slow variable (Lehmann and Deutsch 1992). In this way, $\dot{X}(t) \approx 0$ and $X(t)=\frac{p_{3}}{p_{2}} Y(t)$. As a result, $X(t)$ can be eliminated by substituting it into the first equation (Kovács and Paláncz 2007). Hence, qALPV transformation can be realized by the appropriate choice of the scheduling parameters:

$\rho(t)=\left[\begin{array}{l}\rho_{1}(t) \\ \rho_{2}(t)\end{array}\right]=\left[\begin{array}{c}G(t) \\ \frac{1}{G(t)}\end{array}\right]$,

as $G(t)$, the plasma glucose concentration can be measured.

In this way, qALPV form can be computed:

$\dot{x}(t)=A(\rho(t)) x(t)+B_{1} u(t)+B_{2} d(t)$,
$y(t)=C x(t)$

where $x(t)$ represents the states, $u(t)$ the insulin control input, $d(t)$ the glucose disturbance, while $y(t)$ is the measured output. The parameter matrices are:

$$
\begin{aligned}
& A(\rho(t))=A_{0}+A_{1} \rho_{1}(t)+A_{2} \rho_{2}(t)= \\
& =\left[\begin{array}{cc}
p_{1} & \frac{p_{3}}{p_{2}} G_{b} \\
0 & p_{3}
\end{array}\right]+\left[\begin{array}{cc}
0 & -\frac{p_{3}}{p_{2}} \\
0 & -1
\end{array}\right] \rho_{1}(t)+\left[\begin{array}{cc}
0 & 0 \\
p_{4} Y_{b} & 0
\end{array}\right] \rho_{2}(t),(17 \\
& B_{1}=\left[\begin{array}{l}
0 \\
\frac{1}{V_{L}}
\end{array}\right], B_{2}=\left[\begin{array}{l}
1 \\
0
\end{array}\right], C=\left[\begin{array}{ll}
1 & 0 \\
0 & 1
\end{array}\right] .
\end{aligned}
$$

As a result, by measuring the $G(t)$ glucose value, the parameter matrices can be easily determined. The bounding values of the $\rho(t)$ scheduling parameters determine the parameter polytope with the minimal and maximal point of the vertex. Consequently, if the bounds of the parameter rates are known, they can be implemented in the control design process.

\section{2 qALPV modelling of the Canterbury Model}

Having the origins in the Bergman-model, the same consideration can be done for the Canterbury model regarding the slow variation of the $Q(t)$ (concentration of insulin bounded to interstitial sites) state. In this way, $Q(t)=$ $I(t)$ and the model becomes a second order one.

However, the time dependent variation of the $S_{I}(t)$ insulin sensitivity and the fractional nonlinear form appeared in (2/a) and $(2 / \mathrm{c})$ gives rise to reformulate the $\rho(t)$ scheduling parameters of the qALPV form: $\rho(t)=\left[\begin{array}{l}\rho_{1}(t) \\ \rho_{2}(t) \\ \rho_{3}(t)\end{array}\right]=\left[\begin{array}{c}S_{I}(t) \frac{I(t)}{1+\alpha_{G} I(t)} \\ S_{I}(t) \frac{G_{E}}{1+\alpha_{G} I(t)} \\ \frac{n}{1+\alpha_{I} I(t)}\end{array}\right]$.

Hence, now in (16) the parameter matrices become:

$$
\begin{aligned}
& A(\rho(t))=A_{0}+A_{1} \rho_{1}(t)+A_{2} \rho_{2}(t)+A_{3} \rho_{3}(t)= \\
& =\left[\begin{array}{cc}
p_{G} & 0 \\
0 & 0
\end{array}\right]+\left[\begin{array}{cc}
-1 & 0 \\
0 & 0
\end{array}\right] \rho_{1}(t)+\left[\begin{array}{cc}
0 & -1 \\
0 & 0
\end{array}\right] \rho_{2}(t)+\left[\begin{array}{cc}
0 & 0 \\
0 & -1
\end{array}\right] \rho_{3}(t) \\
& B_{1}=\left[\begin{array}{l}
0 \\
\frac{1}{V}
\end{array}\right], B_{2}=\left[\begin{array}{l}
1 \\
0
\end{array}\right], C=\left[\begin{array}{ll}
1 & 0 \\
0 & 1
\end{array}\right] .
\end{aligned}
$$

Even if the $S_{I}(t)$ can be computed in time and $I(t)$ can be estimated (Wong et al 2006), for further LPV controller design several questions should be investigated, the most important one being the definition of the bounds of the scheduling parameters as precise as it is possible. Namely, the vertex includes the concrete trajectory of the system and by bigger polytope the computation effort also increases. However, $S_{I}(t)$ can be computed only for the next step. To handle this trade-off several ICU measurements should be processed to determine the extreme values of $\rho(t)$.

\section{3 qALPV modelling of the Van Herpe - model}

Being an extension of the Minimal Model, the effect of insulin on net glucose disappearance $(X(t))$ can be also considered as a slow variable $(\dot{X}(t) \approx 0)$. Hence, $X(t)=\frac{p_{3}}{p_{2}}\left(I_{1}(t)-I_{b}\right)$, but due to the $\max ()$ nonlinear term in $(3 / \mathrm{c})$ the $\rho(t)$ scheduling parameters can be chosen as:

$$
\rho(t)=\left[\begin{array}{l}
\rho_{1}(t) \\
\rho_{2}(t) \\
\rho_{3}(t)
\end{array}\right]=\left[\begin{array}{c}
G(t) \\
\frac{1}{G(t)} \\
\delta
\end{array}\right],
$$

where $\delta=\left\{\begin{array}{ll}0, & I_{2}(t)<0 \\ 1, & I_{2}(t)>0\end{array}\right.$.

Hence, now in (16) the parameter matrices become:

$$
\begin{aligned}
& A(\rho(t))=A_{0}+A_{1} \rho_{1}(t)+A_{2} \rho_{2}(t)+A_{3} \rho_{3}(t)= \\
& =\left[\begin{array}{ccc}
\frac{p_{3}}{p_{2}} I_{b}-p_{1} & 0 & 0 \\
0 & -n & 0 \\
\beta \gamma & 0 & -n
\end{array}\right]+\left[\begin{array}{ccc}
0 & -\frac{p_{3}}{p_{2}} & 0 \\
0 & 0 & 0 \\
0 & 0 & 0
\end{array}\right] \rho_{1}(t)+ \\
& +\left[\begin{array}{ccc}
p_{1} G_{b} & 0 & 0 \\
n I_{b} & 0 & 0 \\
-\beta \gamma h & 0 & 0
\end{array}\right] \rho_{2}(t)+\left[\begin{array}{lll}
0 & 0 & 0 \\
0 & 0 & \alpha \\
0 & 0 & 0
\end{array}\right] \rho_{3}(t)
\end{aligned}
$$


$B_{1}=\left[\begin{array}{ccc}\frac{1}{V_{G}} & 0 & 0\end{array}\right]^{T}, B_{2}=\left[\begin{array}{lll}0 & \frac{1}{V_{I}} & 0\end{array}\right]^{T}, C=\left[\begin{array}{lll}1 & 0 & 0 \\ 0 & 1 & 0\end{array}\right]$

Note, that in this situation the scheduling parameters are again associated only to the $G(t)$ glucose value, which can be easily measured, but the $\max ()$ switching function can be hardly handled. However, for the further controller design process the aim of the controller can be to keep $I_{2}(t) \geq 0$. Hence, the $\max ()$ function becomes needless and a linear term can be created by subtracting $I_{2}(t)$ from the $\max ()$ term. In this way a conservative solution can be given.

\section{CONCLUSIONS}

The three mostly commonly used ICU metabolic system models of the literature were examined in this paper. First global control theoretical characteristics were determined using nonlinear analysis proving complete reachability and observability. The transformation of the models in qALPV form was also examined to assess the ability of designing a further robust, nonlinear model-based controller. Particular problems of LPV technique were highlighted.

Further research will be done on robust LPV controller design, as well as comparison of the obtained results and validation on real-data obtained from different patients.

\section{ACKNOWLEDGMENT}

This research was supported in part by Hungarian National Scientific Research Foundation, Grants No. OTKA T69055, T82066.

\section{REFERENCES}

Balas, G.J. (2002). Linear, Parameter-Varying Control and Its Application to a Turbofan Engine. International Journal of Robust and Nonlinear Control, 12(9), 763-796.

Bergman B.N., Ider Y.Z., Bowden C.R., and Cobelli C. (1979). Quantitive estimation of insulin sensitivity. American Journal of Physiology, 236, 667-677.

Bergman, R.N., Philips, L.S., and Cobelli, C. (1981). Physiologic evaluation of factors controlling glucose tolerance in man. Journal of Clinical Investigation, 68, 1456-1467.

Capes, S.E., Hunt, D., Malmberg, K., and Gerstein, H.C. (2000). Stress hyperglycaemia and increased risk of death after myocardial infarction in patients with and without diabetes: a systematic overview. Lancet, 355(9206), 773-778.

Chase, J., Shaw, G.M., Wong, X.W., Lotz, T., Lin, J., and Hann, C.E. (2006). Model-based Glycaemic Control in Critical Care - A review of the state of the possible. Biomedical Signal Processing and Control, 1(1), 3-21.

Chase, J., Shaw, G.M., Le Compte, A., Lonergan, T., Willacy, M., Wong, X.W., Lin, J., Lotz, T., Lee, D., and Hann, C. (2008). Implementation and evaluation of the SPRINT protocol for tight glycaemic control in critically ill patients: a clinical practice change. Critical Care, 12:R49 (doi:10.1186/cc6868).
Griesdale, D.E., de Souza, R.J., van Dam, R.M., Heyland, D.K., Cook, D.J., Malhotra, A., Dhaliwal, R., Henderson, W.R., Chittock, D.R., Finfer, S., and Talmor, D. (2009). Intensive insulin therapy and mortality among critically ill patients: a meta-analysis including NICESUGAR study data. Canadian Medical Association Journal, 180(8), 821-827.

Isidori, A. (1995). Nonlinear control systems, Springer, Berlin.

Kovács, L, Paláncz, B. (2007). Glucose-insulin control of Typel diabetic patients in $\mathrm{H}_{2} / \mathrm{H}_{\infty}$ space via Computer Algebra. Lecture Notes in Computer Science; 4545, 95109.

Kulcsar, B. (2005). Design of Robust Detection Filter and Fault Correction Controller. PhD dissertation, Budapest University of Technology and Economics, Hungary.

Lehmann, E.D., and Deutsch, T.A. (1992). A physiological model of glucose-insulin inter-action in Type1 diabetes mellitus. J. Biomedical Engineering, 14, 235-242.

Lin, J., Lee, D., Chase, J.G., Shaw, G.M., Le Compte, A., Lotz, T., Wong, J., Lonergan, T., and Hann, C.E. (2008). Stochastic modelling of insulin sensitivity and adaptive glycemic control for critical care. Computer Methods and Programs in Biomedicine, 89(2), 141-152.

Le Compte, A.J., Chase, J.G., Lynn, A., Hann, C.E., Shaw, G.M., Wong, X.W., and Lin, J. (2009). Blood Glucose Controller for Neonatal Intensive Care: Virtual trials development and 1st clinical trials, Journal of Diabetes Science and Technology, 3(5), pp. 1066-1081.

Lotz, T., Chase, J.G., McAuley, K.A., Lee, D.S., Lin, J., Hann, C.E., and Mann, J.I. (2006). Transient and steady state euglycemic clamp validation of a model for glycemic control \& insulin sensitivity testing, Diabetes Technology \& Therapeutics, 8(3), 338-346.

Van den Berghe, G., Wouters, P., Weekers, F., Verwaest, C., Bruyninckx, F., Schetz, M., Vlasselaers, D., Ferdinande, P., Lauwers, P., and Bouillon, R. (2001). Intensive insulin therapy in the critically ill patients. The New England Journal of Medicine, 345(19), 1359-1367.

Van den Berghe, G. (2003). Insulin therapy for the critically ill patient. Clinical Cornerstone, 5(2), 56-63.

Van den Berghe, G., Wouters, P.J., Kesteloot, K., and Hilleman, D.E. (2006). Analysis of healthcare resource utilization with intensive insulin therapy in critically ill patients. Critical Care Medicine, 34(3), 612-616.

Van Herpe, T., Espinoza, M., Haverbeke, N., De Moor, B., and Van den Berghe, G. (2007). Glycemia Prediction in Critically Ill Patients Using an Adaptive Modeling Approach. Journal of Diabetes Science and Technology, 1(3), 348-356.

Wong, X.W., Chase, J.G., Shaw, G.M., Hanna, C.E., Lotz, T., Lin, J., Singh-Levett, I., Hollingsworth, L.J., Wong O.S.W., and Andreassen, S. (2006). Model predictive glycaemic regulation in critical illness using insulin and nutrition input: A pilot study. Medical Engineering \& Physics, 28, 665-681.

Wu, F., Grigoriadis, K.M., and Packard, A. (2000). Antiwindup controller design using linear parameter varying control methods. International Journal of Control, 73(12), 1104-1114. 